\title{
The Effects of Electronic Feedback on Medical University Students' Writing Performance
}

\author{
Nooreen Noordin ${ }^{1} \&$ Laleh Khojasteh ${ }^{2}$ \\ ${ }^{1}$ Faculty of Educational Studies, Universiti Putra Malaysia, 43400 UPM, Serdang, Selangore, Malaysia \\ ${ }^{2}$ School of Paramedical Sciences, Shiraz University of Medical Sciences, Shiraz, Iran \\ Correspondence: Laleh Khojasteh, School of Paramedical Sciences, Meshkinfam Str., Shiraz, Iran.
}

Received: December 22, 2020

Accepted: February 13, 2021

Online Published: February 19, 2021

doi:10.5430/ijhe.v10n4p124

URL: https://doi.org/10.5430/ijhe.v10n4p124

\begin{abstract}
This study was designed to see whether electronic feedback positively affects medical students' academic writing performance. Two groups of medical university students were randomly selected and participated in this study. In order to see whether the provision of electronic feedback for the compulsory academic writing course for medical students is effective, the researchers divided 50 medical students to the traditional $(n=25)$ and intervention groups $(n=25)$. Pre-test and post-test were conducted at the beginning and at the end of the semester. Electronic feedback was given to the medical students in the intervention group, while the medical students in the traditional group received the traditional pen and paper feedback. By comparing the scores of two written assignments at the beginning and the end of the semester, regarding the application of electronic feedback, the results showed that not only medical students' overall writing performance improved after providing them electronic feedback, but every single writing component was also enhanced after the intervention. There was a significant difference in the post-test academic writing scores between the traditional and intervention groups $(\mathrm{P}<0.001)$. This difference was not significant in our control group who was given pen-and-paper feedback. In terms of specific writing components, the most affected components in this approach were content followed by organization, language use, vocabulary, and sentence mechanics, respectively. Although this study focused on medical students' academic writing ability and reported the effect of electronic feedback on medical students' writing performance, electronic feedback can be equally beneficial for enhancing student-practitioners' practical clinical skills.
\end{abstract}

Keywords: audiovisual feedback, e-feedback, writing skill, medical students, academic writing

\section{Introduction}

One of the principal issues for living and working in the 21 st century is the ability to communicate views and thoughts in writing. Medical students, too, must obtain proficient scientific writing skills before and after graduation so that they could write accurate arguments on practical themes and clinical subjects as well as writing scholarly articles and publishing them in international journals since it is a critical ability for their career development and social communications (Barroga \& Mitoma, 2019). Despite the dedicated efforts of academicians in enhancing the standards of teaching scientific and academic writing, the performance of medical and many healthcare professionals is not yet satisfactory especially in countries in which English is their foreign language (Barroga \& Mitoma, 2019; Kashefian-Naeeini \& Maarof, 2010). Indeed, investigators and academic strategy promoters recommend that a crucial aspect to cultivating students' writing skills is to discover methods to assist instructors enhance writing instruction. Enhancing writing instruction is a multifaceted task since the feedback procedure is challenging for both instructors and university students (Tuti, Nzinga, \& Njoroge, 2017; Cha, 2014). The impact of effective feedback, according to McKenzie, Burgess, and Mellis (2017), is not only beneficial for medical students to perform clinical procedures and take histories, but also in terms of writing can help them to present their scholarly writing in reports, dissertations, and journal articles which is a sign for interpersonal communication in the scientific community.

Written and verbal feedbacks as primary ways in teaching are constantly available by instructors; however, with the rapid pace of the enhancement in educational technologies, there is a broad spectrum for technology-mediated writing instruction and feedback (Cavaleri, Kawaguchi, Di Biase, \& Power, 2019).

With the aid of electronic feedback (hereafter EF), students can attain an extensive amount of aural feedback out of the classroom and can survive from their previous misinterpretations of their instructors' intention over the 
comments or question marks in assignments in their courses of scientific research and other medical writing courses (Cavaleri et al., 2019). Consistent with Mayer's multimedia learning theory, the visual essence of this kind of multimedia format and the conversational tone used by the instructor make the learning more engaging and productive (Mayer, 2009). Moreover, in terms of academic writing support in higher education, the instructor cares more about the sense, which represents the student's views and ideas rather than only a restricted emphasis on the form and grammar guidelines in their e-feedback (Amin, Patel, Bamania, 2017; Ali, 2016).

Generally, students are reluctant not to only write academic and scientific prose in traditional medical writing courses, but also make meaningful revisions to their texts (Bailey \& Garner, 2010). Moreover, according to Abrahamson (2020), some students are dissatisfied with their grades as they often complain about not knowing where and why they have lost marks even with the use of rubrics. They are also frustrated with the large number of explicit corrective comments on their written assignments. Indeed, some students "do not even bother to collect their work once it has been assessed, preferring to receive their grades by notification from the examination boards" (Duncan, 2007, p. 279). In order to solve this mental image in medical students, instructors should give feedbacks to learners' writings through the application of different methods. This problem is due to the lack of motivation in students; they are not eager enough to make significant attainments in their writings as part of the learning process of a foreign language (Khojasteh, Shokrpour, \& Kafipour, 2015). While a number of studies have concentrated on the role of computerized feedback technologies in amending this problem (e.g., Brick \& Holmes, 2014 and Henderson \& Phillips, 2014), few studies have investigated methods to enhance writing instruction through technologies that facilitate teacher-generated e- feedback. Moreover, teachers' perceptions of the influence of such tools in writing instruction are limited. As noted, studies of teacher e-feedback on medical students' academic writing are quite scarce despite the repeated acknowledgments that the research has given to the importance of teacher feedback and increased use of EF (Ducate \& Arnold, 2017; Elola \& Oskoz, 2017; Ene \& Upton, 2014). Previous studies have suggested the need to compare feedback types (for example e-feedback and traditional feedback or synchronous and asynchronous teacher e-feedback) in academic writing courses and research them in order to grasp a better understanding of the use, effectiveness, and perceptions of EF provided by teachers (Elola \& Oskoz, 2017; Liu \& Sadler, 2003; Schultz, 2000).

In medical education too, electronic feedback not only enhances the quantity but also the quality of feedback presented to medical students (Barroga \& Mitoma, 2019). One of the main reasons behind medical students' enthusiast towards $\mathrm{EF}$ is the accessibility of the feedback for the future references in any time and place (Mayer, 2009). Moreover, Mayer's (2009) cognitive theory of multimedia learning provides ample guidelines on how multimedia instruction can maximize learning. Mayer argues that the best way to increase the capacity of working memory is through using both auditory/verbal channel and visual/pictorial channel simultaneously for the information to be stored in the long-term memory (Mayer, 2005). The adaptation of multimedia can enhance students' engagement and their motivation toward the process of learning; while text never loses its effectiveness, such multimedia features as video and audio, can be of great help to elaborate on concepts that are more complex like writing in a foreign language. With such features, the students can focus and better remember the contents presented to them (Tchoubar, 2014).

\section{Research Questions}

The present study sought to answer the following research questions:

1. Does EF have any significant effect on medical university students' academic writing?

2. Are there any significant differences between the writing components of students in the EF group and traditional group after intervention?

3. If any, which writing component(s) (content, organization, vocabulary, language use, and sentence mechanics) are more affected by EF in medical university students' academic writing?

\section{Methods}

\subsection{Study Design and Participants}

In order to see whether EF affects medical students' academic writing performance, an interventional method was conducted in the fall semester of 2019 at Shiraz Medical University (SUMS). The target population in this study was all medical students enrolled for the compulsory 3-unit academic writing course. The researchers utilized random sampling to choose 50 medical students from all the writing classes that were offered and again randomly divided these students into two groups of intervention and traditional, each with 25 students. 


\subsection{Measures}

\subsubsection{Grading Rubric for Written Assignments}

In order to rate medical students' academic writing performance, each writing sample, both in the pre-test and posttest, was scored using Jacobs, Zinkgraf, Wormuth, Hartfiel, Hughey (1981) rubric, which consists of five differentially weighted scales including content, organization, language use, vocabulary, and mechanics. The content was assessed through some descriptors such as knowledgeable, substantive, and thorough development of thesis and relevant to the assigned topic. Organization was tested in terms of fluency of expression, clarity in the statement of ideas, support, organization of ideas, and sequence as well as development of ideas. Vocabulary was examined in terms of the sophisticated range, effective word choice, word form mastery, and appropriate register. Language use concerned with the use of effective complex construction, agreement, tense, number, and word order. Mechanics dealt with the attention on the use of spelling, punctuation, capitalization, and paragraphing. The scores allocated to each trait were as follows: Content $=25$, Organization $=25$, Language use $=25$, Vocabulary $=15$, and Mechanics $=10$. The total mark was 100 points.

\subsubsection{Screen Capture and Video Recording Software: Snagit}

In order to capture the video displays and audio outputs, the writing instructor in the intervention group used Snagit version 17 throughout the study. This software is created and distributed by TechSmith and was first launched in 1990.

\subsubsection{A Writing Tablet to Give Feedback}

In order to explain concepts visually, encourage collaboration, and support flipped and distance learning, the writing instructor of the intervention group used Intuos Art Creative Pen \& Touch Tablet throughout the study. While Snagit was capturing the entire session, the instructor used a writing tablet to provide feedback to the medical students. A sample shot of student' writing sample can be seen in the Appendix.

\subsection{Inter-Rater Reliability}

To provide a rather objective assessment of each written passage in both pretest and posttest, two raters (TESL PhD holders, teaching at Shiraz University of Medical Sciences) scored the students' writing assignments on the pretest and posttest based on the rubric. To measure inter-rater reliability, the researchers applied Pearson product-moment correlation based on the average ratings on scores for the six individual components of each writing task. To this end, inter-rater reliability of the scores given by two raters was examined. The reliability coefficient for the total score was .778 followed by $.761, .747, .643$, and .678 respectively, for the components content, organization, language use, vocabulary, and mechanics. This indicates that a high consistency exists between the two raters regarding the way they scored the participants' knowledge of writing and its components. Moreover, the correlation coefficients were all significant indicating that both raters were significantly consistent in scoring the participants writing tasks.

\subsection{Procedure}

Participants in the two groups were instructed for 17 weeks ( 2 sessions each week and one and half-hour class time) and were given the same assignments. They were asked to submit eight paragraphs and eight essays throughout the entire course. On class time, students were trained on the format and structure of essay writing and were assigned to write their assignments at home. After writing their drafts in a Word document, students in the traditional group had to print their assignments out and hand in their assignments in person, whereas intervention group students had to turn in their assignments electronically.

Although the traditional group received the same instructions as the intervention group, the conventional corrective feedback was provided to the medical students of the traditional group, identifying errors and correcting them on the learners' written essays. The writing instructor of the traditional group was asked to give a thorough feedback to her students in terms of content, organization, vocabulary, language use, and mechanics, using only pen and paper and if deemed necessary, face-to-face elaboration on the provided feedback that is almost always inevitable in traditional writing classes.

In the intervention group, students were trained on the first two sessions on accessing, interpreting, and using received digital feedback. Then the writing instructor provided EF to the medical students, using a screen-capturing tool. Video commentaries started with praising the positive aspects of the paper and highlighting parts that needed improvement supported with some model examples. The aim here was not to indicate all the errors, but to point out error patterns and guide medical students in correcting them. Online resources and links were also inserted to give further guidance. The output MP4 files were then sent to students via WhatsApp. 
The data were collected in two phases, namely pre-test phase as well as post-test phase. Pre-test paragraphs of medical students were collected in the very first day medical students (both in the traditional group and intervention one) attended writing classes. Students were asked to write about the following topic: What are the main causes of obesity among individuals? This topic was chosen because medical students had enough background knowledge about the mentioned writing topic. In the second phase that was post-test, the data were collected within 17th week of the semester. Notably, due to the stress of the final exam (Teranishi Martinez, Kock, \& Cass, 2011) and its potential effect on students writing, the researchers did not intend to collect students' writing tasks which they produce in the final examination, but rather the data were collected in the ordinary class time in week 17 of the semester under the topic: How to minimize sickness in the society. This topic, too, is health-related and medical students had enough background knowledge about it.

\subsection{Statistical Analysis}

In order to answer the research questions, the researchers analyzed the collected data by SPSS Software (version 22.0). To see if EF has any significant effect on medical university students' writing, Mann-Whitney U test was used. To see which writing component(s) (content, organization, vocabulary, language use, and sentence mechanics) are more affected by EF in medical university students' writing Kruskal Wallis test was used.

\section{Results}

Firstly, to ensure that the participants were homogenous in their writing ability, they were required to complete a writing task before instruction as pre-test. Later, the writings were marked and analyzed by an independent sample t-test.

Then, Kolmogorov-Smirnova's test of normality was used to specify if parametric or non-parametric tests should be used. According to the results of the test, the distribution of the scores for all of the examined components was not normal; therefore, non-parametric tests were applied.

To ensure both groups were homogenous before starting the intervention, pre-test mean scores of both groups were calculated as depicted in Table1.

Table 1. Descriptive Statistics

\begin{tabular}{ccccc}
\hline & Group & N & Mean & Std. \\
\hline \multirow{2}{*}{ Content } & Traditional & 25 & 11.82 & 5.17 \\
& EF & 25 & 10.30 & 5.58 \\
Organization & Traditional & 25 & 10.35 & 4.5 \\
& EF & 25 & 9.92 & 4.8 \\
Language Use & Traditional & 25 & 12.98 & 3.31 \\
& EF & 25 & 12.33 & 4.22 \\
Vocabulary & Traditional & 25 & 9.15 & 1.97 \\
& EF & 25 & 8.60 & 2.95 \\
Mechanics & Traditional & 25 & 5.80 & 1.46 \\
& EF & 25 & 5.10 & 1.4
\end{tabular}

By comparing mean scores for traditional and experimental groups, in content, organization, language use, and vocabulary components, the traditional group outperformed the EF one. However, only in one writing component, mechanics, the EF group outperformed the traditional group. To ensure if these differences are statistically significant, Mann-Whitney U test was run.

Table 2. Mann-Whitney U test for pre-test mean scores of different writing components between traditional and intervention groups

\begin{tabular}{llllll}
\hline $\begin{array}{l}\text { Writing } \\
\text { component }\end{array}$ & Content & Organization & Vocabulary & Language Use & Sentence Mechanic \\
\hline $\begin{array}{l}\text { Mann-Whitney } \\
\text { U }\end{array}$ & 189 & 180 & 171 & 168 & 163 \\
Wilcoxon W & 459 & 451 & 442 & 438 & 436 \\
\hline
\end{tabular}




\begin{tabular}{llllll}
\hline $\mathrm{Z}$ & -.783 & -.845 & -1.395 & -1.425 & -1.408 \\
$\begin{array}{l}\text { Asymp. Sig. } \\
\text { (2-tailed) }\end{array}$ & .385 & .354 & .342 & .299 & .284 \\
\hline
\end{tabular}

According to Table 2, Asymp. Sig. for all the writing components is greater than .05; therefore, it can be concluded that there is no significant difference between pre-tests of both traditional and intervention groups in terms of different writing components. Therefore, we concluded that both groups were homogenous before the intervention.

To answer the first research question and to see if EF has any significant effect on medical students' writing in the intervention group, pre-test and post-test mean scores of students in the intervention group were calculated and compared. As descriptive statistics in Table 3 shows, the means for different components of the students' writing before $\mathrm{EF}$ were lower than their means after intervention.

Table 3. Paired sample descriptive statistics for intervention group

\begin{tabular}{|c|c|c|c|c|c|}
\hline \multicolumn{3}{|c|}{ instruction } & \multirow{2}{*}{$\begin{array}{l}\text { Mean } \\
10.30\end{array}$} & \multirow{2}{*}{$\begin{array}{l}\mathrm{N} \\
25\end{array}$} & \multirow{2}{*}{$\begin{array}{l}\text { SD } \\
5.58\end{array}$} \\
\hline $\mathrm{EF}$ & Pair 1 & Pre-content & & & \\
\hline & & Post-content & 20.64 & 25 & 2.40 \\
\hline & Pair 2 & Pre-organization & 9.92 & 25 & 4.80 \\
\hline & & Post-organization & 20.43 & 25 & 2.90 \\
\hline & Pair 3 & Pre-vocabulary & 8.60 & 25 & 2.95 \\
\hline & & Post-vocabulary & 12.40 & 25 & 1.44 \\
\hline & Pair 4 & Pre-language use & 12.33 & 25 & 4.22 \\
\hline & & Post-language use & 20.32 & 25 & 2.56 \\
\hline & Pair 5 & Pre-sentence mechanics & 5.10 & 25 & 1.40 \\
\hline & & Post-sentence mechanics & 8.10 & 25 & 1.61 \\
\hline
\end{tabular}

To answer the second research question and see if the differences between pre- and post-test scores were statistically significant, Wilcoxon test was conducted as shown in the following table. As the $\mathrm{P}$ values for the mean scores shows, all the components of writing were found lower than .05 , so it is concluded that these differences are statistically significant; that is, the students outperformed after provision of EF in comparison to the time before it.

Table 4. Wilcoxon Signed- Rank Test for intervention group

\begin{tabular}{|c|c|c|c|c|c|c|}
\hline \multicolumn{2}{|c|}{ Instruction } & \multirow{2}{*}{$\begin{array}{l}\text { Pre-content } \\
\text { Post-content }\end{array}$} & \multirow{2}{*}{$\begin{array}{l}\text { Pre-organization } \\
\text { Post-organization }\end{array}$} & \multirow{2}{*}{$\begin{array}{l}\text { Pre-vocabulary } \\
\text { Post- } \\
\text { Vocabulary }\end{array}$} & Pre-language use & \multirow{2}{*}{$\begin{array}{l}\text { Post sentence } \\
\text { mechanics - pre- } \\
\text { sentence mechanics }\end{array}$} \\
\hline & & & & & $\begin{array}{l}\text { Post language } \\
\text { use }\end{array}$ & \\
\hline \multirow[t]{2}{*}{$\mathrm{EF}$} & $\mathrm{Z}$ & -3.300 & $-3.305^{b}$ & $-3.283^{b}$ & $-3.298^{b}$ & $-3.327^{b}$ \\
\hline & $\begin{array}{l}\text { Asymp. } \\
\text { Sig. } \\
\text { (2-tailed) }\end{array}$ & 0.000 & 0.000 & 0.000 & 0.000 & 0.000 \\
\hline
\end{tabular}

To see if there is any significant difference between the writing components of students in the intervention group and the traditional group, a comparison of posttest mean scores of EF group and traditional group is presented in Table 5. As this table shows, mean scores of writing components in the EF group are higher than their counterparts in the traditional group. 
Table 5. Descriptive statistics for the differences between post-test mean scores of EF and traditional groups

\begin{tabular}{lllll}
\hline & Instruction & Mean & N & Std. Deviation \\
\hline post content & traditional & 15.22 & 25 & 2.84 \\
post organization & EF & 20.64 & 25 & 2.40 \\
& traditional & 15.32 & 25 & 3.19 \\
post vocabulary & EF & 20.43 & 25 & 2.90 \\
& traditional & 10.31 & 25 & 1.80 \\
Post language use & EF & 12.40 & 25 & 1.44 \\
& traditional & 14.63 & 25 & 3.10 \\
Post-sentence mechanics & EF & 20.32 & 25 & 2.56 \\
& traditional & 6.09 & 25 & 0.92 \\
& EF & 8.10 & 25 & 1.61
\end{tabular}

To find out if the differences in Table 5 are statistically significant, Man-Whitney test was conducted as shown in Table 6. Since the $\mathrm{P}$ value for all writing components are smaller than 0.05 , it is concluded that the EF group outperformed the traditional one in the post-test.

Table 6. Mann-Whitney Test

\begin{tabular}{llllll}
\hline & Post content & $\begin{array}{l}\text { Post } \\
\text { organization }\end{array}$ & $\begin{array}{l}\text { Post } \\
\text { vocabulary }\end{array}$ & $\begin{array}{l}\text { Post language } \\
\text { use }\end{array}$ & $\begin{array}{l}\text { Post sentence } \\
\text { mechanics }\end{array}$ \\
\hline Mann-Whitney U & 0.000 & 0.000 & 16.000 & 12.000 & 62.500 \\
Wilcoxon W & 253.000 & 253.000 & 269.000 & 265.000 & 315.500 \\
Z & -6.003 & -5.980 & -5.630 & -5.675 & -4.714 \\
Asymp. Sig. (2-tailed) & 0.000 & 0.000 & 0.000 & 0.000 & 0.000 \\
\hline
\end{tabular}

And finally, to respond to the third research question (If any, which writing component(s) (content, organization, vocabulary, language use, and sentence mechanics) are more affected by EF?), Kruskal Wallis test was conducted to see if the ranking based on the post-test mean scores of the writing components, shown in Table 7, are confirmed to be statistically significant or not.

Table 7. Descriptive Statistics and Ranking of writing components in intervention group

\begin{tabular}{ccccc}
\hline & $\mathrm{N}$ & Mean & Std. & Rank \\
\hline Content & 25 & 20.64 & 2.4 & 1 \\
Organization & 25 & 20.43 & 2.9 & 2 \\
Language use & 25 & 20.32 & 2.56 & 3 \\
Vocabulary & 25 & 12.4 & 1.44 & 4 \\
Mechanics & 25 & 8.1 & 1.61 & 5 \\
\hline
\end{tabular}


As shown in Table 7, the highest mean belongs to the content component, followed by organization, language use, vocabulary, and sentence mechanics, respectively. However, Kruskal Wallis test was run to see whether the differences between mean scores of all writing components in EF are statistically significant. As depicted in Table 8, $\mathrm{P}$-value (.014) is lower than .05.

Table 8. Test statistics a, b

\begin{tabular}{ll}
\hline & Writing component scores \\
\hline Chi-square & 8.580 \\
df & 4 \\
Asymp. Sig. & .014 \\
\hline
\end{tabular}

a. Kruskal Wallis Test

b. Grouping variables: writing components

\section{Discussion}

The first research question asked: Does EF have any significant effect on medical university students' writing? The result of this question showed that in terms of all the writing components, content, organization, language use, vocabulary, and mechanics, the group that received EF outperformed the one that received a traditional feedback. In terms of the effect of EF on students' academic writing, our result supports another study conducted by Cavaleri et al. (2019); however, in terms of audio versus written feedback, our result is not consistent with Morris and Chikwa (2016) who reported a non-significant difference between these two modes of feedback on students' academic performance. One main reason perhaps is that based on the multimedia principles, using two channels of communication, auditory and visual, is more effective than anyone used in isolation (Mayer, 2009). The second reason of this inconsistency might be the fact that Morris and Chikwa (2016) just compared the effect of their auditory feedback and written feedback within a very short period of time (from the first assignment to the second assignment). Therefore, a longer intervention might have resulted a better students' performance.

As for the second research question specifically, the result showed that there are significant differences between the writing components of students in the EF group and traditional group after the intervention. Our result is in disagreement with another study conducted by Kerr et al. (2016) who compared two groups of students (one receiving traditional feedback and one receiving e- feedback) and found that despite the positive perceptions of writing instructors as well as students toward EF, this form of feedback did not have any significant impact on students' attainment. One possible reason behind this result is that the researchers only used three consecutive written assignments (comparisons of performance change between assignments 1 to 3 ) to evaluate the impact of $\mathrm{EF}$ on students' attainment. We believe such a short period might reduce the opportunity for any kind of impact to take place.

Considering the combined results of the first and second research questions, our result showed that not only medical students' overall writing performance improved after giving them EF, but every single writing component was also enhanced after the intervention. This is probably because one-minute narrating audio feedback can be considered equal to six minutes writing feedback according to Lunt and Curran's (2010). For example, Thompson and Lee (2012) who employed Jing screen-recording software to record five-minute audio-visual commentary on student's work reported that the majority of students perceived that they understood video comments in a more meaningful way than the written comments. This is because teachers can speak the student's language with the screencast software in ways that are absent in the written comments.

Furthermore, in terms of the positive effect we found in the second research question, Cavanaugh and Song (2014) believe when students respond to e-feedback, they appear to make universal revisions rather than simply editing the surface level errors. With e-feedback, students not only hear what is confusing about a sentence, but also instructor's voice or tone help deepen their impressions on feedback and, therefore, they are more willing to attempt revision (Kerr, Dudau, Deeley, Kominis, \& Song, 2016). This promising result partially agrees with the results of another study carried out by Hyde (2013) who examined EF method for e-submissions with 40 undergraduate students. According to the subjects, feedback was more detailed and personalized and students' views on the feedback were found to be positive.

However, in Hyde's (2013) study, certain drawbacks in using e-feedback have also been mentioned. The first problem was related to the university's website (VLE) from which students could have access to their feedback. This method of accessibility to their feedback, according to the students, was not practical all the time. In addition, Jing, the software 
with which the writing instructor recorded the feedbacks had a 5-minute time limit, which, reportedly, was not enough to provide a thorough feedback to the students. The first drawback mentioned in Hyde's study was overcome by using WhatsApp, with which all medical students had access to. According to Kerr et al. (2016), when digital content is readily available to students, they are motivated to engage with the feedback more than once and to take additional time reflecting to their feedback. For overcoming the second problem mentioned in Hyde's study, the writing instructor in our study used another software, Snagit, which allowed the writing instructor to take as long as she needs to record feedback for students. Using opinionnaires, interviews and learner's composition papers, Tajallizadeh Khob and Rabi (2014) indicated that audiovisual meaning-focused feedbacks were not only effective in increasing the learners' motivation to write but also changed the negative view of the learners towards writing which eventually helped them further their efforts in achieving educational progress in their written assignments.

As for the third research question, our results showed that in the descending order content, organization, language use, vocabulary, and mechanics were affected by EF, and there are significant differences between the above mentioned five writing components. Although our prior assumption was that because our medical students did not have prior experience in writing in English, they would focus more on vocabulary and grammatical rules (August, 2002), our finding suggests that this can be changed when novice writers are offered the appropriate tools and are provided with the right type of feedback.

Vocabulary and mechanics were the two least affected writing components in our study. In terms of vocabulary, one possible assumption is that since the medical students were exposed to health-related topics at their general English classes as well as 3-unit compulsory ESP class prior taking a writing course, they were already competent with their word choices, word forms, and register. As for mechanics, it is assumed that in a process-oriented approach, it is normally the content that is prioritized over grammatical accuracy and mechanics (Ferris, 2011).

Our findings confirm some other previous studies too (see Lavolette, Polio, \& Kahng, 2014; Li, 2018). These studies have shown that when electronic platforms are used, positive effects are observed regarding some aspects of writing, especially content and organization. These studies have highlighted the influential roles of immediacy of online feedback. It can be argued that according to $\mathrm{Li}$ (2018), for more proficient learners, direct corrective feedback is more effective for writing components like content and organization. This finding is consistent with the finding of another study conducted by Elola and Oskoz (2017) who compared Word comments with screencasts as means for providing feedback. In this study, advanced Spanish learners could improve the content, structure, and organization of their writing since, according to them, the screencast comments were lengthier and more focused. Despite their familiarity with Word comments, Spanish learners perceived the screencast to be more natural.

\section{Conclusions and Pedagogical Implications}

The results of our study showed that EF was much more efficient than traditional feedback. Accordingly, the effect of hearing the comments and observing the paper simultaneously seems to have a great positive impact on the understanding and development of medical students' writing skill compared with the traditional feedback, which lacks these aspects. Moreover, in EF, the instructor has more chances for delivering a clear and comprehensive feedback through mentioning examples and sharing useful links for further guidance, and he/she can praise the positive points of the writing as well. These qualities lead to a better comprehension of the weaknesses and strengths of each writing and motivates medical students in learning and correcting the errors in further assignments. The application of technology is a challenging endeavor according to some experts (e.g. Lavolette et al., 2014) and the use of multimedia is an insurmountable enterprise (Tajalizadeh Khob \& Rabi, 2014) which paved the way for technical revolution in the changing world. Some fundamental impacts have been exerted in educational settings and electronic feedback made its subtle way into today's classrooms.

Regardless of the comparison of audiovisual and traditional feedback, the effect of EF on five basic elements of writing, namely, content, organization, vocabulary, language use, and sentence mechanics is remarkable. The most affected component in this approach was content followed by organization, language use, vocabulary, and sentence mechanics, respectively. It can be concluded that the instructor's comments on the content component were more rich and efficient. However, it can be inferred that the impact of sentence mechanics relating to the rules of the written language, such as capitalization, punctuation, and spelling, as less explanatory issues, have not attracted students' attention greatly.

Although this study focused on medical students' writing ability and the effect that EF has on medical students' writing performance, EF can be equally beneficial for enhancing student-practitioners' practical clinical skills. According to Cham and Cochrane (2019), EF is not only timely, but also provides medical students with an opportunity of self-reflection and personalized feedback. 
From a pedagogical point of view, this research presented valuable insights for medical instructors as well as medical students. The results of this study widen the perspective of medical instructors in that they can recognize novel methods of teaching and providing feedbacks in the way that is both time and cost effective. Medical and clinical instructors, with this awareness, can apply more appropriate strategies in order to enhance medical students' learning. Correspondingly, this evaluation is beneficial to medical learners in that they can comprehend which one of the studied feedbacks is more useful and practical in their learning procedure.

The main implication following our results is that EF should be implemented for higher education and teachers should be trained to implement appropriate novel approaches for giving feedback, especially after the emergence of COVID-19 and school lockdowns.

\section{Abbreviations}

EF: Electronic Feedback; SUMS: Shiraz University of Medical Sciences

\section{References}

Abrahamson, E. (2010). Enhancing students' understanding of formative assessment through video-feedback on an undergraduate sports rehabilitation program. Higher Education Academy. Retrieved from http://www.heacademy.ac.uk/assets/hlst/documents/case_studies/147_abrahamson_video-feedback.pdf

August, D. (2002). Transitional programs for English language learners: Contextual factors and effective programming (Report No. 58). Baltimore, MD: Center for Research on the Educational of Students Placed at Risk. Retrieved from ERIC database.

Ali, AD. (2016). Effectiveness of using screencast feedback on EFL students' writing and perception. English Language Teaching, 9(8), 106-121. https://doi: org/10.5539/elt.v9n8p106

Amin, RR., Patel, R., \& Bamania, P. (2017). The importance of feedback for medical students' development. Advances in Medical Education and Practice, 8, 249-251. https://doi.org/10.2147/AMEP.S134419

Bailey, R., \& Garner, M. (2010). Is the feedback in higher education assessment worth the paper it is written on? Teachers' reflections on their practices. Teaching in Higher Education, 15(2), 187-198. https://doi.org/10.1080/13562511003620019

Barroga, E., \& Mitoma, H. (2019). Improving Scientific Writing Skills and Publishing Capacity by Developing University-Based Editing System and Writing Programs. $J$ Korean Med Sci, 34(1), e9. https://doi.org/10.3346/jkms.2019.34.e9

Brick, B., \& Holmes, J. (2014). Using screen capture for student feedback. Paper presented at the Eleventh International Conference Cognition and Exploratory Leaning in Digital Age, Porto, PT.

Cavaleri, M., Kawaguchi, S., Di Biase, B., \& Power, C. (2019). How recorded audio-visual feedback can improve academic language support. Journal of University Teaching \& Learning Practice, 16(4). Retrieved from https://ro.uow.edu.au/jutlp/vol16/iss $4 / 6$

Cavanaugh, AJ. \& Song, L. (2014). Audio feedback versus written feedback: Instructors' and students' perspectives. Journal of Online Learning and Teaching, 10(1), 122-138.

Cha, YJ. (2014). Effects of blended peer feedback modes on learners' writing performance and perspectives. Multimedia-Assisted Language Learning, 17(2). https://doi.org/10.15702/mall.2014.17.2.11

Cham, KM., \& Cochrane, AL. (2019). A digital resource to assess clinical competency. The Clinical Teacher. https://doi.org/10.1111/tct.13030

Ducate, L., \& Arnold, N. (2012). Computer-mediated feedback: Effectiveness and student perceptions of screen-casting software versus the comment function. In G. Kessler, E. Oskoz, \& I. Elola (Eds.), Technology across writing contexts and tasks (pp. 31-56). San Marcos, TX: CALICO Publications.

Duncan, N. (2007). Feed-forward: Improving students' use of tutors' comments. Assessment and Evaluation in Higher Education, 32(3), 271-283. https://doi.org/10.1080/02602930600896498

Elola, I., \& Oskoz, A. (2017). Writing with 21st century social tools in the L2 classroom: New literacies, genres, and writing practices. Journal of Second Language Writing, 36(1), 52-60. https://doi.org/10.1016/j.jslw.2017.04.002

Ene, E., \& Upton, TA. (2014). Learner uptake of teacher electronic feedback in ESL composition. System, 46(1), 80-95. https://doi.org/10.1016/j.system.2014.07.011 
Ferris, DR. (2011). Treatment of error in second language student writing. 2nd Ed. Ann Arbor, MI: University of Michigan Press. https://doi.org/10.3998/mpub.2173290

Henderson, M., \& Phillips, M. (2014). Technology enhanced feedback on assessment. Paper presented at the 26th Australian Computers in Educational Conference, Adelaide, South Australia.

Hyde, E. (2013). Talking Results-trialing an audio-visual feedback method for e-submissions. Innovative Practice in Higher Education, 1(3). Retrieved from http://journals.staffs.ac.uk/index.php/ipihe/article/view/37/0 Accessed August 7

Jacobs, HL., Zinkgraf, SA., Wormuth, DR., Hartfiel, VF., \& Hughey, JB. (1981). Testing ESL composition: A practical approach. Rowley, MA: Newbury House.

Kashefian-Naeeini, S., \& Maarof, N. (2010). Language learning strategies used by ESL students. International Journal of Learning, 17(8). https://doi.org/10.18848/1447-9494/CGP/v17i08/47224

Kerr, J., Dudau, A., Deeley, S., Kominis, G., \& Song, Y. (2016). Audio-Visual Feedback: student attainment and student and staff perceptions. UK: University of Glasgow. Retrieved from http://eprints.gla.ac.uk/119844/7/119844.pdf

Khojasteh, L., Shokrpour, \& N., Kafipour, R. (2015). EFL students' perception toward class participation in General English courses, Indian Journal of Fundamental and Applied Life Sciences, 5(2) 3198-3207.

Lavolette, E., Polio, C., \& Kahng, J. (2014). The accuracy of computer-assisted feedback and students' responses to it. Language, Learning \& Technology, 19(2), 50-68.

Li, S. (2018). Corrective feedback. In Liontas J. et al. editors, The TESOL encyclopedia of English language teaching. Blackwell. https://doi.org/10.1002/9781118784235.eelt0247

Liu, J., \& Sadler, R. (2003). The effect and affect of peer review in electronic versus traditional modes on L2 writing. Journal of English for Academic Purposes, 2(3), 193-227. https://doi.org/10.1016/S1475-1585(03)00025-0

Mayer, R. E. (2005). Cognitive Theory of Multimedia Learning. In R. E. Mayer (Ed.), The Cambridge Handbook of Multimedia Learning (pp. 31-48). New York: Cambridge University Press. https://doi.org/10.1017/CBO9780511816819.004

Lunt, T., \& Curran, J. (2010). Are you listening please? The advantages of electronic audio feedback compared to written feedback. Assessment \& Evaluation in Higher Education, 35(7), 759-769. https://doi.org/10.1080/02602930902977772

Mayer, RE. (2009). Multimedia learning (2nd ed.). Cambridge University Press. https://doi.org/10.1017/CBO9780511811678

McKenzie, S., Burgess, A., \& Mellis, C. (2017). Interns reflect: the effect of formative assessment with feedback during pre-internship. Adv Med Educ Pract, 8, 51-56. https://doi.org/10.2147/AMEP.S114480

Morris, C., \& Chikwa, G. (2016). Audio versus written feedback: exploring learners' preference and the impact of feedback format on students' academic performance. Active Learning in Higher Education, 7(2), 125-137. https://doi.org/10.1177/1469787416637482

Schultz, J. (2000). Computers and collaborative writing in the foreign language curriculum. In M. Warschauer, \& R. Kern (Eds.) Network-based language teaching: Concepts and practice (pp. 121-150). Cambridge, UK: Cambridge University Press. https://doi.org/10.1017/CBO9781139524735.008

Tajalizadeh Khob, M., \& Rabi, A. (2014). Meaning-focused audiovisual feedback and EFL writing motivation. Journal of Language and Translation, 4(2), 61-70.

Tchoubar, T. (2014). Effective use of multimedia explanations in open e-learning environment fosters student success, Educ. Technol, 4 (1). https://doi.org/10.7763/IJIET.2014.V4.370

Teranishi Martinez, Ch., Kock, N., \& Cass, J. (2011). Pain and Pleasure in Short Essay Writing: Factors Predicting University Students' Writing Anxiety and Writing Self-Efficacy. Journal of Adolescent \& Adult Literacy, 54(5). https://doi.org/10.1598/JAAL.54.5.5

Thompson, R., \& Lee, MJ. (2012). Talking with students through screen casting: Experimentations with video feedback to improve student learning. The Journal of Interactive Technology and Pedagogy, 1(1), 17-26. 
Tuti, T., Nzinga, J., \& Njoroge, M. (2017). A systematic review of electronic audit and feedback: intervention effectiveness and use of behavior change theory. Implementation Sci. https://doi.org/10.1186/s13012-017-0590-z

\section{Appendix}

Screenshot of a medical student's assignment and the feedback provided using Touch Tablet. Taken by the researcher

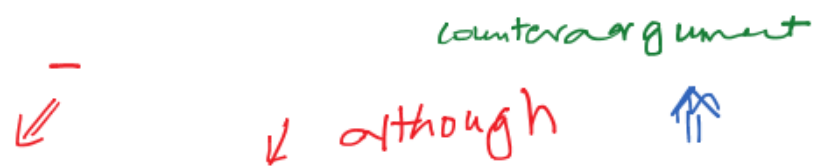

Horror movies have many side effects on watchers. altghou many advocates of this genre can people

claim that watching a horror movie cane give you a great amount of excitement, this excitement Their - $\ell$ can affect on your mind and cause such mentalproblem as depression,startle, and so forth. Dr.

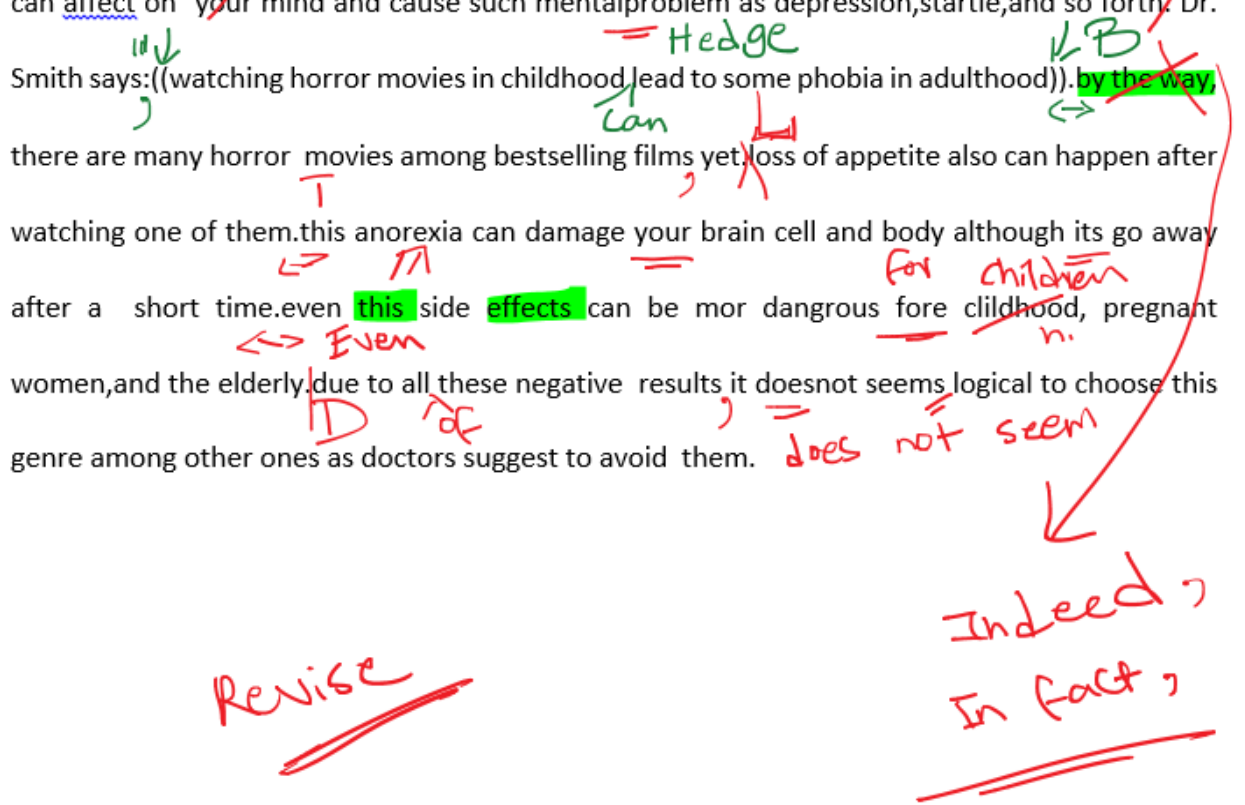

\section{Copyrights}

Copyright for this article is retained by the author(s), with first publication rights granted to the journal.

This is an open-access article distributed under the terms and conditions of the Creative Commons Attribution license (http://creativecommons.org/licenses/by/4.0/). 